\title{
Myxozoan transmission via actinospores: new insights into mechanisms and adaptations for host invasion
}

\author{
D. M. KALLERT ${ }^{1 *}$, S. PONADER ${ }^{2}$, E. ESZTERBAUER ${ }^{3}$, M. EL-MATBOULI ${ }^{1}$ and W. HAAS ${ }^{2}$ \\ ${ }^{1}$ Institute of Zoology, Fish Biology and Fish Diseases, University of Munich, Kaulbachstraße 37, D-80539 Munich, Germany \\ ${ }^{2}$ Institute for Zoology I, University Erlangen, Staudtstraße 5, D-91058, Erlangen, Germany \\ ${ }^{3}$ Veterinary Medical Research Institute, Hungarian Academy of Sciences, Hungária krt 21, H-1143 Budapest, Hungary
}

(Received 25 April 2007; revised 4 Fune 2007; accepted 6 Fune 2007; first published online 30 Fuly 2007)

\section{SUMMARY}

Various mechanisms that enable and improve transmission success of myxozoan actinospore stages towards fish hosts are described, based upon a combination of experimental data and functional analysis of morphological characters. For this purpose, laboratory-reared actinospores of Myxobolus cerebralis, Myxobolus parviformis, Henneguya nuesslini and Myxobolus pseudodispar were employed to exemplarily investigate aspects of host attachment and invasion. The process of polar filament discharge of M. cerebralis actinospores was analysed, showing that full discharge occurs in less than $10 \mathrm{msec}$. Additionally, a mechanism that rapidly contracts the discharged filament after discharge is described for the first time. Its purpose is most likely to bring the actinospore apex rapidly into intimate contact with the surface of the host. Unlike M. cerebralis, $M$. parviformis actinospores did not discharge polar filaments after mechanical and chemical stimulation, suggesting a different mode of triggering. For H. nuesslini actinospores, experimental results indicated that polar filament discharge is independent of external calcium-ion concentration but is influenced by osmolality. After attachment of an actinospore and prior to penetration into the host, an ensheathed unit ('endospore'), containing the sporoplasm, was emitted from the valves in a manner which varied from species to species. Experimentally induced sporoplasm emission was time-dependent and was found to be independent of polar filament discharge in H. nuesslini. Remarkably, it could be concluded that the sporoplasm is able to recognize host-stimuli while still within the intact spore. An updated summary of the sequential course of events during host recognition and invasion by actinospores is given.

Key words: Myxozoa, Myxobolus cerebralis, polar capsule discharge, actinospore, host invasion, sporoplasm.

\section{INTRODUCTION}

Along with the high importance of fish diseases caused by Myxozoa, studies of the life-cycles, parasite-host-relationships and developmental aspects of the phylum have resulted in a better understanding of life-history traits (Kent et al. 2001). Most myxozoans probably exhibit a complex life-cycle, developing alternately in vertebrates (mostly teleosts) and invertebrates (mostly annelids). Non-motile, waterborne actinospores, shed by the aquatic invertebrate hosts, comprise the means of conveyance of the infective stages towards fish. Actinospores are assumed to be only viable for several days to few weeks (Markiw, 1992; Yokoyama et al. 1993; Xiao and Desser, 2000). Hence, special adaptations for rapid host recognition and attachment are essential for successful parasite transmission during the brief period of spore viability.

The discharge of their characteristic polar filaments anchors the actinospore to the fish surface.

* Corresponding author: Institute of Zoology, Fish Biology and Fish Diseases, University of Munich, Kaulbachstraße 37, D-80539 Munich, Germany. Tel: +49892180 3561. Fax: +49892180 3912. E-mail: kallert@zoofisch.vetmed.uni-muenchen.de
Gills, skin and the buccal cavity have been confirmed as portals of entry for $M$. cerebralis, while Thelohanellus hovorkai and Sphaerospora truttae prefer entry via the gills (Yokoyama and Urawa, 1997; Holzer et al. 2003). Tetracapsuloides bryosalmonae and Henneguya ictaluri enter via the skin, while the former was also reported to infect gills (Morris et al. 2000) and the latter was additionally found in the intestine and the buccal cavity (Belem and Pote, 2001 ; Longshaw et al. 2002). Consumption of infected oligochaetes may also aid infection in some species. Attachment to and penetration of hosts by actinospores, and subsequent migration of the amoeboid sporoplasm, should be considered as separate steps, which possibly require different host signals (Kallert et al. 2005a). Kallert et al. (2005a) demonstrated that $M$. cerebralis actinospores become mechanically excitable after chemo-sensitization by host mucus prior to polar filament discharge. Such a combination of signals inhibits erroneous reactions upon contact with non-host aquatic organisms or any dead matter. However, no mechanoperceptive structure has yet been described in myozoans.

Many physiological aspects of this evolutionary successful parasite group remain unclear (Yokoyama, 2003) and a better understanding of host-invasion in Myxozoa requires information on 
their morphological and behavioural adaptations to parasitism and on the physiological requirements for host-recognition and host-attachment. Elucidation of these mechanisms is valuable for our understanding of the epidemiology of disease outbreaks caused by Myxozoa in fish populations. Moreover, artificial induction of spore responses may be an effective biological control approach to prevent great losses in hatchery and wild fish populations. Presenting preliminary findings with laboratorycultured myxozoans, the present paper shows by which means myxozoan parasites ensure transmission success during the difficult task to recognize and invade fish hosts.

MATERIALS AND METHODS

\section{Parasite cultivation}

Myxospores were isolated by tissue homogenisation for 2-5 min at $11500 \mathrm{rpm}$ using an Ultra Turrax (IKA Labortechnik, Staufen, Germany). Tissue remnants were then removed by passing the homogenate through $100 \mu \mathrm{m}$ mesh filters. The homogenate was then topped up to $500 \mathrm{ml}$ with tap water with the suspension settling overnight at $4{ }^{\circ} \mathrm{C}$. All fish were kept at $16-18{ }^{\circ} \mathrm{C}$ under a constant flow of well water and fed on conventional fish flakes. Oligochaete cultures were maintained in 5 litre plastic containers containing a $5-6 \mathrm{~cm}$ layer of autoclaved mud and coarsely grained sand $(1: 1 \mathrm{v} / \mathrm{v})$ and were held at $12-15{ }^{\circ} \mathrm{C}$ in the dark. Oligochaetes were fed weekly using a mixture of frozen Artemia, spray-dried Spirulina (MaBitech) and frozen lettuce. Autoclaved mud from the settling pond of a salmonid hatchery was added weekly. Only well water free of copper and chlorine was used for oligochaete cultures.

Henneguya nuesslini and host fish were obtained from a local hatchery (Bavaria, Germany). Myxospores were either obtained from muscle or pieces of the tail of adult, naturally infected brown trout. Cultivation of the parasite was conducted according to Kallert et al. (2005b). Four to seven-month-old (3-6 cm) parasite-free brook trout (Salvelinus fontinalis) and brown trout (Salmo trutta) were used for infection with actinospores from infected oligochaete cultures. Myxobolus parviformis actinospores originated from an established parasite culture described by Kallert et al. (2005c), using myxospores obtained from cysts isolated from gill filaments of laboratoryinfected bream. For $M$. cerebralis cultivation, infected cultures of Tubifex tubifex were obtained from the long-term established laboratory cultures at the Institute of Zoology, Fish Biology and Fish Diseases of the University of Munich (Germany). Additionally, fresh oligochaetes (>200000 individuals) from the salmonid hatchery were transferred to aerated plastic beakers (4 litre) and used for infection with $M$. cerebralis myxospores after a monitoring period (including control cultures without myxospore addition) as described by Kallert et al. (2005a). Myxobolus pseudodispar originated from naturally infected oligochaetes from the salmonid hatchery. Actinospores from single oligochaetes were used for infection of laboratory-reared myxozoanfree roach (Rutilus rutilus) at a dose of $\sim 2000$ actinospores per fish. The $18 \mathrm{~S}$ rDNA sequence of this parasite isolate was submitted to GenBank (Accession no. EF466088) to enable future identification, as different isolates of spores morphologically identified as $M$. pseudodispar can show high variability (up to $4 \%$ difference) in these sequences. The isolate examined was most similar to $M$. pseudodispar ex Blicca bjoerkna (GenBank Accession no. AF466654).

Unless otherwise noted above, oligochaetes from a laboratory stock were infected by addition of $\sim 0 \cdot 5-2 \times 10^{6}$ myxospores after incubating the freshly prepared oligochaete cultures for at least 1 week. Non-exposed control cultures did not produce notable amounts of actinospores. All species form Triactinomyxon-type actinospores (TAMs). They were harvested from oligochaete cultures by filtration using $20 \mu \mathrm{m}$ nylon meshes or from single oligochaetes isolated in cell well plates according to the method of Yokoyama et al. (1991).

\section{Test substrates}

The mucus substrates for experimental use were prepared as described previously (Kallert et al. 2005 c). Adult rainbow trout (Oncorhynchus mykiss) and carp (Cyprinus carpio) were obtained from a local distributor. Common bream (Abramis brama) and roach were caught in the river Aisch, Germany. Where necessary, mucus was concentrated by removing water from the solution by partial lyophilization in a SpeedVac, deionized water was used for dilution. Artificial incubation media (standard fresh water 'SFW 100' according to Meier-Brook (1978), containing 100 ppm $\mathrm{Ca}^{2+}$ ) were prepared by dissolving the respective salts in deionized water. In 1 volume of $\mathrm{Ca}^{2+}$-free water $(7 \mathrm{mOsm} / \mathrm{kg})$, the osmolality was restored according to the value of the $\mathrm{Ca}^{2+}$-containing mixture $(12 \mathrm{mOsm} / \mathrm{kg})$ by addition of $\mathrm{NaCl}$. Osmolality was measured in triplicate using $150 \mu \mathrm{l}$ samples by freezing-point-depression using an Osmometer Automatic (Knauer, Berlin), calibrated with deionized water and a $400 \mathrm{mOsm} \mathrm{NaCl}$ solution $(12 \cdot 687 \mathrm{~g} / \mathrm{kg})$. All osmolality values given refer to unbuffered substrates.

\section{Polar filament discharge}

Discharge rates. Polar filament discharge rates were determined as described by Kallert et al. (2005a). Briefly, $9 \mu$ of buffered test substrate were added to 
$21 \mu 1$ of buffered spore suspension on slides and covered with a cover-slip $(20 \times 20 \mathrm{~mm})$, followed by mechanical stimulation for $3 \mathrm{~s}$ at $50 \mathrm{~Hz}$ using a Mini Shaker Type 4810 (Brüel \& Kjœr, Copenhagen). Buffered deionized water served as control in all experiments. All media containing parasites or test substrates were adjusted to $\mathrm{pH} 7.5$ (5 mM sodium phosphate buffer). Spore suspensions were stored at $12{ }^{\circ} \mathrm{C}$ and test substrates were kept on ice during use. Whenever possible, a blind protocol was used by coding the test substrates.

Discharge process. To visualize the process of polar filament discharge, video sequences were recorded using an Axiophot (Zeiss) and a video camera (Canovision EX1 $8 \mathrm{~mm}$, Canon). M. cerebralis actinospores were placed on a glass slide in $30-40 \mu \mathrm{l}$ of water covered with a cover-slip and $4-12 \mu \mathrm{l}$ of a $30 \%$ aqueous $\mathrm{NH}_{3}$ solution were added slowly from the side to induce filament firing. Still frames were taken as screenshots from the Video using Ulead Video Studio 7.0 SE software.

$\mathrm{Ca}^{2+}$-dependency. To investigate the role of $\mathrm{Ca}^{2+}$ in the surrounding medium on polar filament discharge, H. nuesslini actinospores were transferred from their original medium to SFW ('Standard fresh water' according to Meier-Brook, 1978) with and without $\mathrm{Ca}^{2+}$. The original water of the actinospore suspension was replaced by transferring separate filtration units $(10 \mathrm{ml}$ plastic tubes with $20 \mu \mathrm{m}$ mesh as bottom) in $5 \mathrm{ml}$ cups with $\mathrm{SFW}$ for $30 \mathrm{~min}$ and repeated 4 times, changing the medium each time. Polar filament discharge rates were measured using carp mucus homogenate $(1 \mathrm{mg} / \mathrm{ml}$ final concentration). Individual controls were included showing the discharge rates for actinospores incubated in each SFW mixture separately.

Discharge stimuli. The possible combination of chemical and mechanical stimuli for polar filament discharge in $M$. parviformis actinospores was tested as described by Kallert et al. (2005c). Briefly, immobilized single actinospores were exposed to a sequence of stimuli comprising $2.5 \mu \mathrm{l}$ of control (buffered) water, mechanical stimulation (3-fold apical tipping), $2 \cdot 5 \mu \mathrm{l}$ of host mucus and repeated mechanical stimulation with $10 \mathrm{sec}$ observation intervals between all steps. To test whether the actinospores were able to discharge at all, a saturated solution of urea was applied.

\section{Sporoplasm release}

To determine if actinospores had an intrinsic mechanism to cause their apical sutures to open upon polar filament discharge to enable sporoplasm release, H. nuesslini actinospores were microscopically observed after addition of rainbow trout mucus
(1 $\mathrm{mg} / \mathrm{ml}$ final concentration). The spore suspension $(40 \mu \mathrm{l})$ was placed on a slide and plastilin spacers were used to ensure that pressure from the cover-slip did not affect sporoplasm release. Discharged and undischarged spores were observed for $15 \mathrm{~min}$ using a stereomicroscope. Sporoplasm release (emergence of at least $1 / 3$ of the primary cell mass) with and without preceding polar filament discharge was recorded. The period from substrate mixing until sporoplasm release was recorded.

To confirm the cellular integrity of $M$. parviformis sporoplasms after emergence from the surrounding sheath, fluorescein-diacetate (FDA) staining was used as described by Yokoyama and Urawa (1997) and Markiw (1992) on spore isolates incubated in carp mucus. Sporoplasm emission from $M$. pseudodispar actinospores was recorded using a digital camera (Moticam 2000, Motic) under a stereomicroscope, after a $1: 3(\mathrm{v} / \mathrm{v})$ addition of carp mucus.

\section{Statistical methods}

Statistical analysis was performed using SPSS for Windows. Where necessary, data were arcsine square root transformed to obtain approximately normally distributed data; homogeneity was controlled using the Levene test. Mean values and standard errors were calculated from the transformed data and were retransformed thereafter. Differences between means were tested for statistical significance by a multivariate comparison procedure (Tukey HSD multiple $t$-test after one-way-ANOVA). Correlation between binominal variables was tested by crosstabulation followed by calculation of Yates' continuity correction as well as the Phi-value and the contingency coefficient as symmetric measures. Mantel-Haenszel statistics (homogeneity of the odds ratio) was used to test for independence in response between the binary variables.

\section{RESULTS}

\section{Polar filament discharge}

Discharge process. Video analysis of polar filament discharge in $M$. cerebralis actinospores showed that complete extrusion requires less than $10 \mathrm{msec}$ (Fig. 1A-C). Most notably, the polar filament first rapidly elongates, then contracts shortly after discharge to about half its length (Fig. 1D and E). This 'dragging mechanism' could be observed to pull the whole spore body about $35 \mu \mathrm{m}$ along the slide by means of the sticky filament (Fig. 2A-C).

$\mathrm{Ca}^{2+}$-dependency. H. nuesslini actinospores showed a significant discharge rate in SFW with $\mathrm{Ca}^{2+}$ $(P<0.001$ vs control), but discharged their polar filaments less frequently when the SFW was $\mathrm{Ca}^{2+}$ deficient $(P<0 \cdot 05$, Table 1$)$. When the osmolality of 

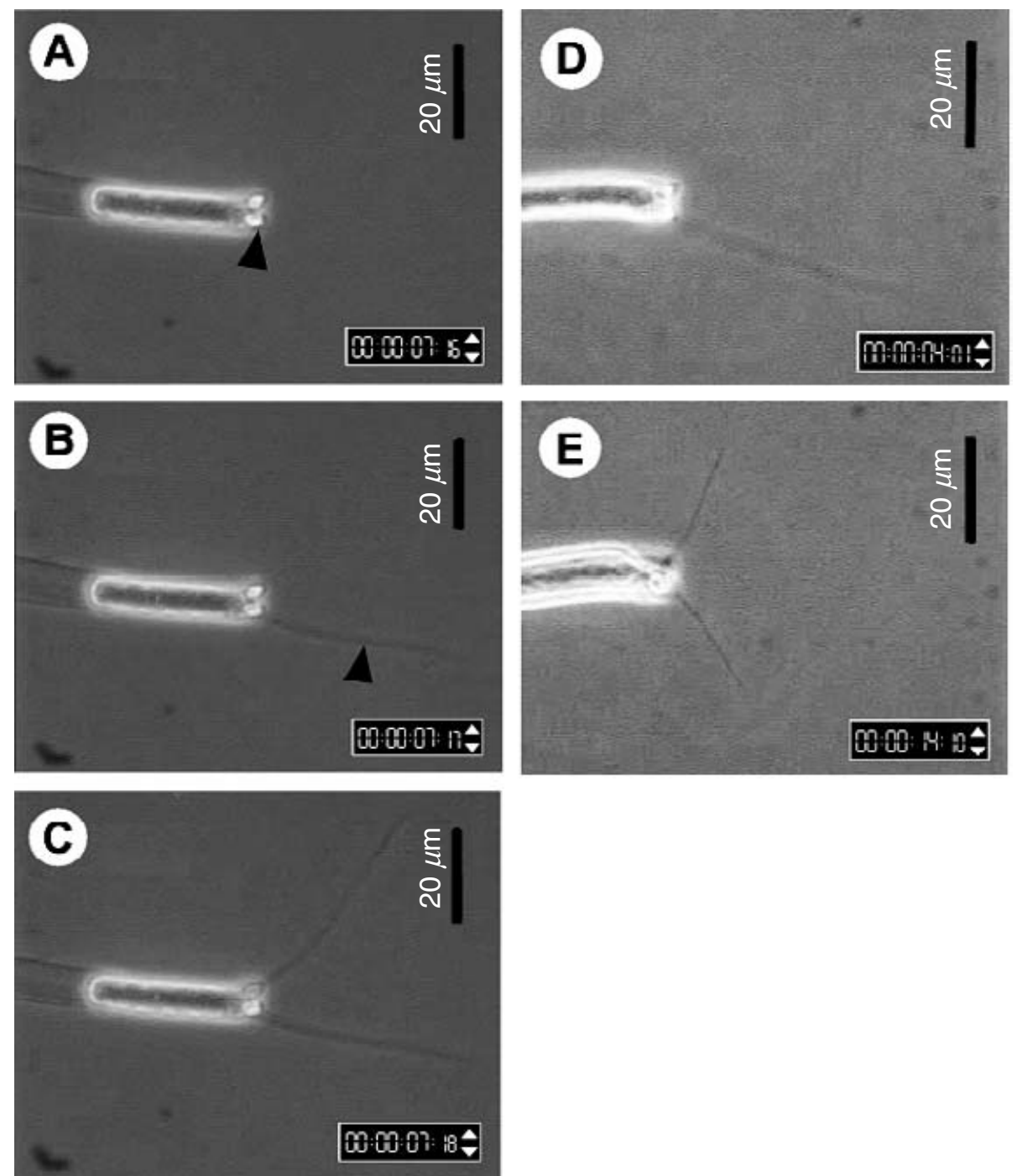

Fig. 1. Polar filament discharge of Myxobolus cerebralis actinospores induced by addition of 30\% ammonia (phasecontrast optics). (A) Actinospore apex with polar capsules (arrowhead). (B) The same spore having discharged one filament (arrowhead) 0.01 s later. (C) Discharge of a second filament 0.01 s later, both still elongated. (D) Different actinospore during polar filament discharge showing elongation of the first filament. (E) Both abridged discharged filaments of the same spore $10 \mathrm{~s}$ later. Counter included from the original video footage shows centiseconds (small scale) and sec (large scale).

the $\mathrm{Ca}^{2+}$-deficient $\mathrm{SFW}(7 \mathrm{mOsm} / \mathrm{kg})$ was adjusted to the value of $\mathrm{Ca}^{2+}$-containing water $(12 \mathrm{mOsm} / \mathrm{kg})$, the discharge rate was equal to that measured in $\mathrm{Ca}^{2+}$-containing water $(P=0 \cdot 57$, Table 1$)$. However, the responses in $\mathrm{Ca}^{2+}$-deficient water (with and without adjusted osmolality) were not significantly different from the respective controls (without mucus addition) $(P=0.3$ and 0.08 respectively). The responses to controls (without mucus) differed among the media (Table 1). Therefore, the discharge rates obtained in controls could be subtracted from the responses caused by mucus addition in the respective media for equalization. As a consequence, the discharge rate in $\mathrm{Ca}^{2+}$-containing water was significantly higher than that in $\mathrm{Ca}^{2+}$-deficient water with adjusted osmolality $(P<0 \cdot 05)$. The responses in both $\mathrm{Ca}^{2+}$-free media were not significantly different from each other $(P=0 \cdot 7)$.
Discharge stimuli. Of 29 single $M$. parviformis actinospores, only $3(10 \cdot 3 \%)$ did react after the first mechanical stimulation, and 1 further specimen $(3 \cdot 8 \%)$ of the remaining reacted after mucus addition. None of the 25 remaining spores reacted after the ensuing mechanical stimulation within the observation period of $10 \mathrm{sec}$. General discharge ability of the actinospores was tested by addition of a saturated urea solution, showing that all spores had a functioning attachment apparatus.

\section{Sporoplasm release}

The period the amoeboid sporoplasm required to leave the valve structure after stimulation by mucus was determined for $H$. nuesslini actinospores. The majority of sporoplasms left the valves within $6 \mathrm{~min}$, whereas most were emitted around 5 min (Fig. 3, 

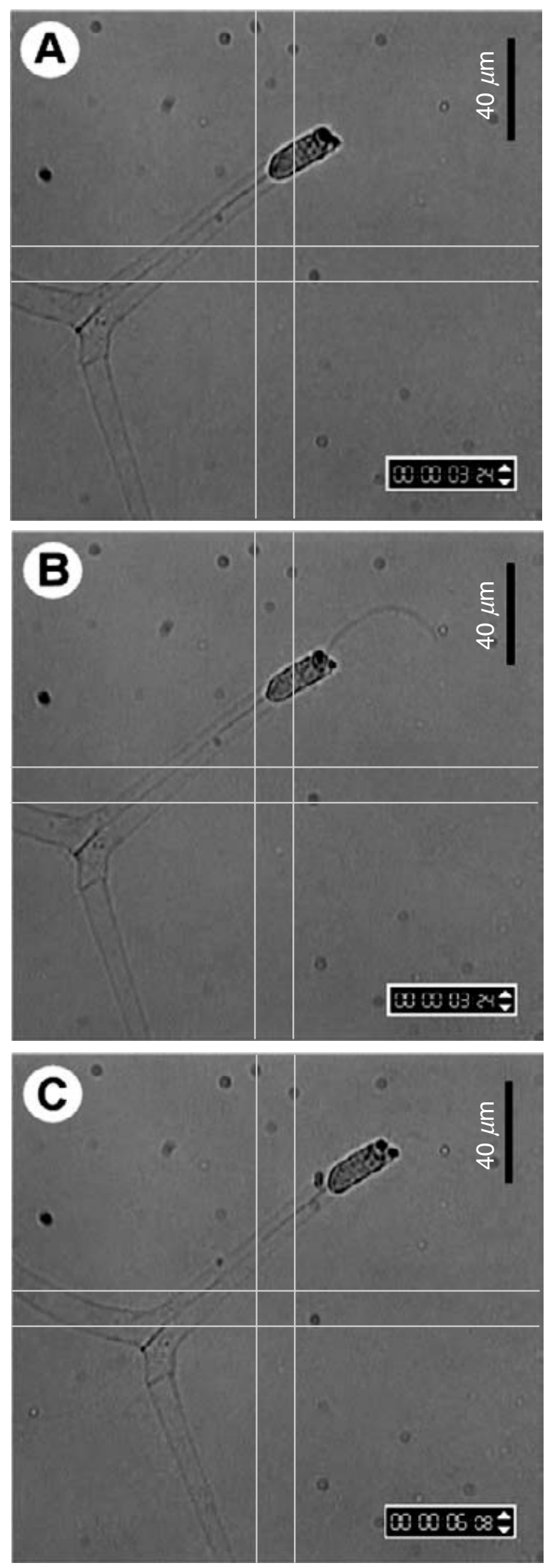

Fig. 2. Polar filament discharge of Myxobolus cerebralis actinospore induced by addition of $30 \%$ ammonia (bright-field optics, grid shows actinospore movement). (A) Actinospore prior to discharge. (B) The same spore with fully discharged filament. (C) The same spore with abridged filament less than $3 \mathrm{~s}$ later; note different with the mean time of emission around $5.4 \mathrm{~min}$, S.D. $=2 \cdot 8$ ). The observation of discharged and undischarged $H$. nuesslini actinospores for $15 \mathrm{~min}$ after stimulation by mucus homogenate revealed that among actinospores with discharged polar filaments, $60 \cdot 6 \%$ kept their sporoplasm inside the spore valve (109 individuals counted), while for non-discharged actinospores, $28 \cdot 4 \%$ released their sporoplasms (95 individuals counted). In most undischarged actinospores in which the sporoplasm did not emerge, the amoeboid mass exhibited characteristic movements within the style of the spore (also observed in all other species) that were absent without mucus incubation. There was very weak correlation between the responses, as shown by the Phi-value of $0 \cdot 114$ and the contingency coefficient of $0 \cdot 113$ (with a significance of $0 \cdot 104)$. Additionally, according to Mantel-Haenszel's chi-square analysis, there is no strong relationship between the two reactions $(P=0 \cdot 14)$. Therefore, the sporoplasm emission reaction is per se independent from polar filament discharge (no linear correlation) in $H$. nuesslini actinospores. Nevertheless, $39 \cdot 4 \%$ more sporoplasms were released when polar filaments were discharged, but release was not an imperative consequence after filament discharge.

Observing actinospores reacting to mucus, we could discern 2 different modes of sporoplasm emission in $M$. parviformis and $M$. pseudodispar. In one mode, the sporoplasm emerged as an amoeboid mass from the valve cells as typically seen on slides after incubation in fish mucus. Alternatively, a sheathed unit (corresponding to the 'endospore' described by Janiszewska, 1955) was emitted, out of which subsequently the sporoplasm emerged. The cellular integrity of the actively moving amoeboid primary cell could be confirmed by FDA-staining of $M$ parviformis 'endospores' (Fig. 4). Unlike $M$. parviformis (see Kallert et al. 2005c), the $M$. pseudodispar valve cell did not open in a splayed finger-like manner to release the sheath unit, and it was rather released from the valve cells as a 'plug' (Fig. 5).

\section{DISCUSSION}

The experimental outcome along with a step-by-step analysis of morpho-physiological aspects and the reactions actuated by actinospores during host invasion provide valuable information on myxozoan transmission. An understanding of how actinospores recognize and enter the fish host is not only of importance concerning epidemiology of myxozoans,

location after movement along the slide. Counter included from the original video footage shows milliseconds (small scale) and sec (large scale). 
Table 1. Effect of $\mathrm{Ca}^{2+}$-ions on polar filament discharge of Henneguya nuesslini actinospores during response to carp mucus homogenate $(1 \mathrm{mg} / \mathrm{ml})$

(The actinospores were transferred to artificial medium ('Standard fresh water' (SFW) according to Meier-Brook, 1978). $\mathrm{NaCl}$ was used for osmolality equilibration of $\mathrm{Ca}^{2+}$. deficient water. Actinospores and substrates were mixed on a slide $(21+9 \mu \mathrm{l})$ with application of vibrations $(3 \mathrm{~s}, 50 \mathrm{~Hz}$, Amplitude $0.5 \mathrm{~mm})$. Letters indicate a significant difference (ab, $P \leqslant 0 \cdot 001$; ABCD, $P \leqslant 0 \cdot 05$; Tukey HSD). Total number of actinospores counted per substrate 286-398 (8 replicates).)

\begin{tabular}{lll}
\hline \hline Substrate & $\begin{array}{l}\text { Discharge } \\
\text { rate }[\%]\end{array}$ & s.E. \\
\hline SFW $+\mathrm{Ca}^{2+}$ & $21 \cdot 3^{\mathrm{a}}$ & $+3 \cdot 5 /-3 \cdot 3$ \\
SFW $+\mathrm{Ca}^{2+}+$ mucus & $42 \cdot 1^{\mathrm{b} A B}$ & $+4 \cdot 4 /-4 \cdot 3$ \\
SFW $-\mathrm{Ca}^{2+}$ & $15 \cdot 0^{\mathrm{bCD}}$ & $+2 \cdot 4 /-2 \cdot 3$ \\
SFW $-\mathrm{Ca}^{2+}+$ mucus & $26 \cdot 8^{\mathrm{A}}$ & $+3 \cdot 3 /-3 \cdot 1$ \\
SFW $-\mathrm{Ca}^{2+}+\mathrm{NaCl}$ & $23 \cdot 9^{\mathrm{B}}$ & $+2 \cdot 7 /-2 \cdot 6$ \\
SFW $-\mathrm{Ca}^{2+}+\mathrm{NaCl}+$ mucus & $33 \cdot 5^{\mathrm{CD}}$ & $+3 \cdot 5 /-3 \cdot 4$ \\
\hline \hline
\end{tabular}

the information is useful also to researchers performing laboratory work with specimens of this phylum. For this study, we chose suitable species to investigate each of the mechanisms and tried to give comparative information about differences between certain species.

With respect to polar filament discharge, the observed speed of discharge and the length of the polar filament indicate that actinospores need close contact between their apical region and the host surface for successful attachment. In $M$. cerebralis actinospores, there is a putative chemically triggered thigmoperceptive structure (Kallert et al. 2005a), suggested by the observation that the actinospores only discharged their filament when a chemical (mucusderived) signal was present prior to physical contact. An intrinsic retraction mechanism was always observed immediately after discharge of the filament in several species. Its purpose could be to mediate ultimately close contact with the viscous fish surface or to pull the 'endospore'-construct out of the valve envelope. The actinospores thereby have developed an excellent mechanism to pull their apical region tightly towards the host surface, enabling the sporoplasm to directly enter the epidermal layer. The artificially induced discharge without mechanical stimulation for visualization was only possible using ammonia as an effector for practical reasons. The use of ammonia instead of a natural trigger did not influence the characteristic course of the reaction. It remains unknown how the initial elongation and subsequent contraction of the polar filament actually occurs, but it is likely that either proteinaceous conformation changes upon hydration or the stored energy due to the well-known filament twist play a role.

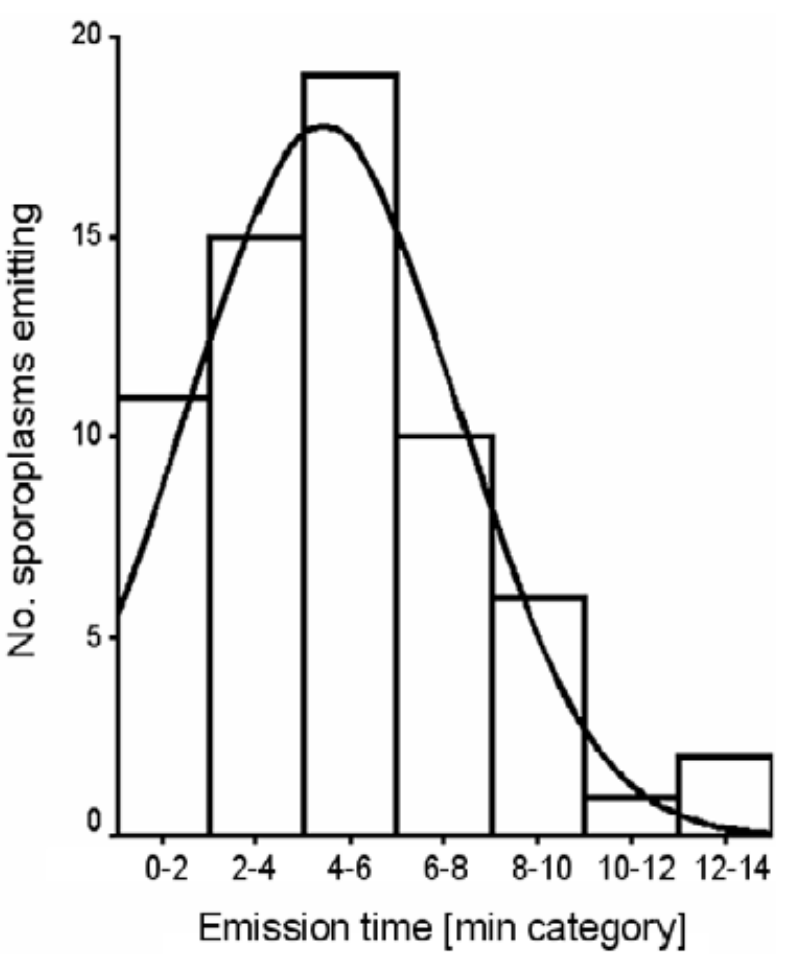

Fig. 3. Duration until onset of the emission response of Henneguya nuesslini sporoplasms after stimulation with mucus in time categories representing the period (2 min per category) after stimulation in which the emission movement was observed (64 actinospores counted). A curve has been plotted showing Poisson-distribution.

Uspenskaya (1982) assumed $\mathrm{Ca}^{2+}$-ions to be involved in the polar filament discharge mechanism and suggested that it is an active process due to contractile proteins. The role of calcium as an effector or even the driving force behind the filament extrusion is also implicated in cnidarians : removal of calcium from the medium inhibited discharge of nematocysts in some species (Santoro and Salleo, 1991 ; Kawaii et al. 1997 ; Russell and Watson, 1995). Additionally, calcium plays a role in cell-signalling in cnidae-bearing complexes (Cannon and Wagner, 2003). By $\mathrm{Ca}^{2+}$-replacement experiments, we showed that external $\mathrm{Ca}^{2+}$ was not a major effector for the discharge mechanism in $H$. nuesslini actinospores, but it appeared that the osmolality of the surrounding medium had to exceed a certain value to enable normal discharge rates. When the effect of osmolality differences was considered and the different responses in control media were subtracted from the discharge rates with mucus, $\mathrm{Ca}^{2+}$-ions indeed seemed to play a role. Discharge rates in $\mathrm{Ca}^{2+}$-containing water were doubled compared to those in $\mathrm{Ca}^{2+}$-deficient water at the same osmolality. However, in $\mathrm{Ca}^{2+}$-free medium with restored osmolality by $\mathrm{NaCl}$-addition, filament discharge rates were higher than in media with $\mathrm{Ca}^{2+}$, indicating that eventually only an artificial effect of $\mathrm{NaCl}$ was observed. This may play a role in membrane 

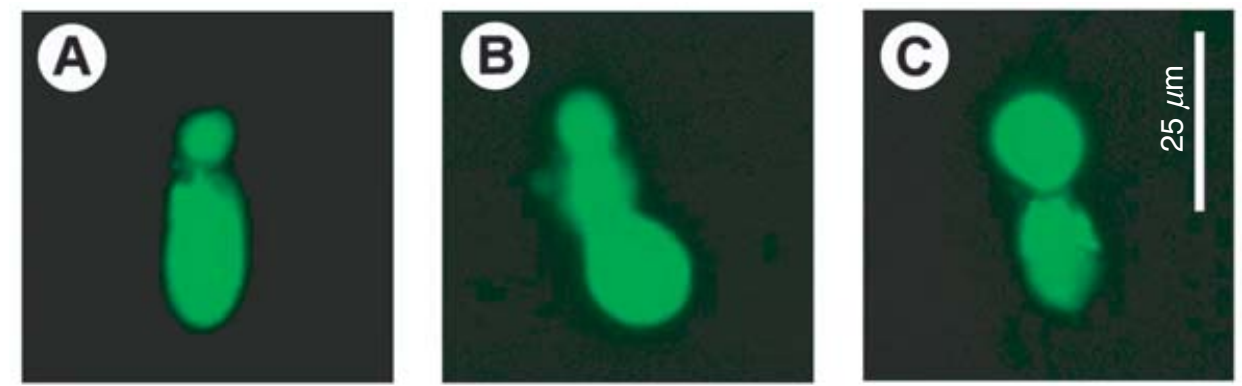

Fig. 4. Sporoplasm emission of Myxobolus parviformis sheath unit ('endospore') induced by addition of bream mucus after fluorecein-diacetate-staining. (A) Ball-like pseudopodium emerging first. (B) Apical opening and active emergence of the sporoplasm. (C) Fully emerged sporoplasm with sheath bag attached; note membrane staining of actively emerged amoeboid primary cell.

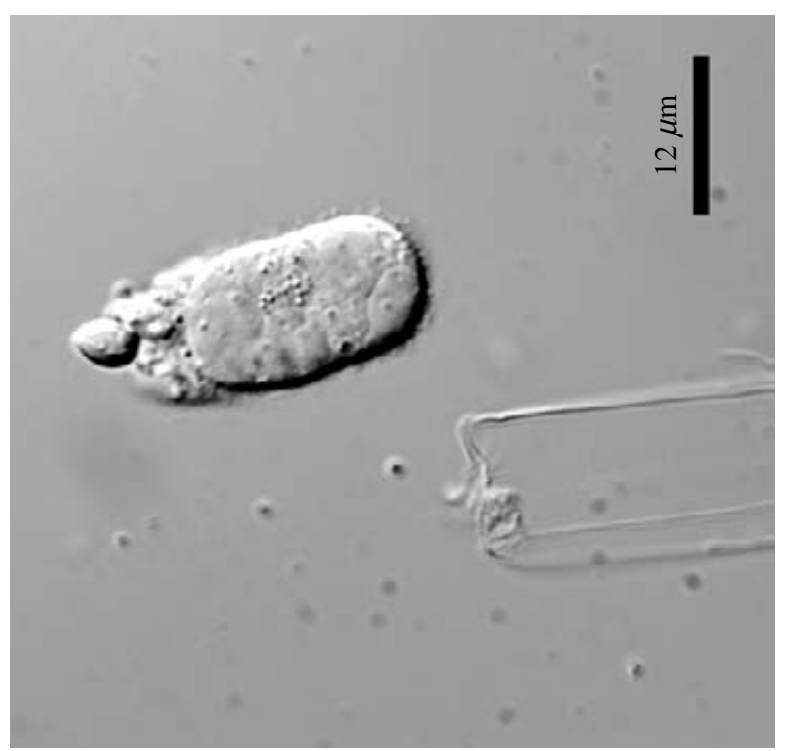

Fig. 5. Expulsion of Myxobolus pseudodispar sheat unit ('endospore') induced by addition of roach mucus; note the plug-like apical architecture with no polar capsules left in the valve cells.

conductivity or osmotic balance of the parasite primary cell and thus influence polar filament discharge. However, we assume that exterior $\mathrm{Ca}^{2+}$ ion-concentration does not play a significant role, considering that discharge was never fully abolished in $\mathrm{Ca}^{2+}$-deficient media. Whether actinospores are able to adjust to media with lower osmolality after prolonged incubation, should be further investigated.

In sporoplasm emission experiments, most $H$. nuesslini sporoplasms left their valve shell after about 5 min after little or no mechanical stimulation and with or without prior polar filament discharge - a result comparable with the data of Yokoyama et al. (2006). These authors further observed 'slow' and 'fast' reactions of 2 myxozoan species infecting different fish hosts. In Thelohanellus hovorkai actinospores, sporoplasms were released over a $30 \mathrm{~min}$ exposure time to host mucus, while Myxobolus arcticus actinospores reacted similarly to $M$. cerebralis in the current study. The aurantiactinomyxon type of $T$. hovorkai has a similar apical ultrastructure as $M$. parviformis triactinomyxon spores with rather counter-sunk polar capsules located below the apical valve cell margin (Kallert et al. 2005c), in contrast to fast-reacting species such as $M$. cerebralis and $H$. nuesslini showing polar capsules with protruding tips. This may be an ecological adaptation in response to a need for rapid host recognition. Similarly, the low discharge rates and negative reactivity of $M$. parviformis actinospores in this work may be explained if this parasite requires an extended time to react, a feature which could reflect a specialization towards a certain host invasion route (e.g. via gills or oral uptake) or an environment that bears a higher risk of unintentional mechanical stimulation, for instance by large amounts of plankton. A more rigid apical structure may be an adaptation for prolonged viability, as these actinospores may be better protected or less sensitive than, for example, $H$. nuesslini actinospores. A difference in host preference is apparent between 'quickly' and 'slowly'-reacting parasites; as the former infect stream inhabitants, while the latter seem to prefer bottom feeders in standing waters. However, $M$. pseudodispar is a fast-reacting species predominantly found in slow waters, which would represent an exception to the rule. However, the slow mode of sporoplasm emission observed by Yokoyama et al. (2006) may also be the result of increased mechanical sensitivity of the triactinomyxon-type actinospores, as no further mechanical stimulus was applied. This may have extended the period required for reaction of $T$. hovorkai specimens, as fewer polar filaments would have discharged. Surprisingly, $M$. parviformis actinospores did not elicit a similar reaction to a combination of chemical and mechanical stimulation compared to $M$. cerebralis. It is not known whether the incubation time of the chemical stimulus was too short for this species.

Although the experimental conditions of the sporoplasm emission experiments with $H$. nuesslini certainly do not completely mimic contact with a real 
A

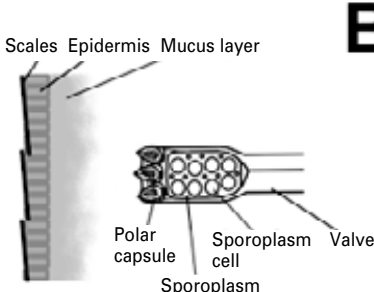

B

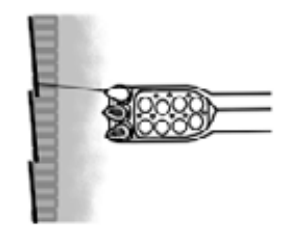

F

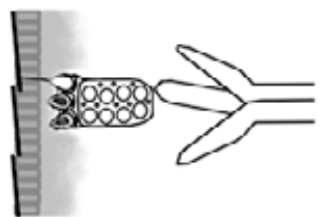

C

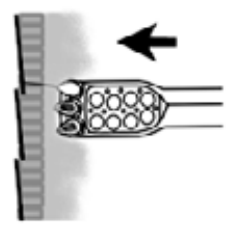

G

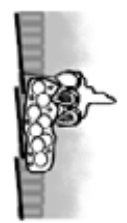

D

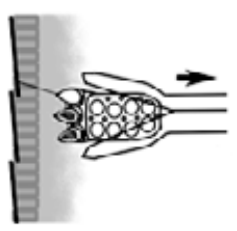

H

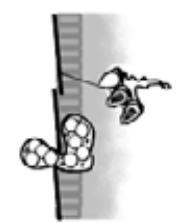

Fig. 6. Schematical course of the events during host invasion by triactinomyxon-type actinospores. (A) Actinospore apical region encountering fish host surface, chemical sensitization. (B) Polar filament discharge after mechanical stimulus upon contact. (C) Adduction (arrow) of the actinospore apex for close contact to the host surface by means of filament constriction. (D) Opening of the apical valves among specific sutures by means of water current traction (arrow). (E) Release of the attached 'endospore', discarding of the valve shell. (F) Active emergence of the sporoplasm. (G) Fully emerged sporoplasm leaving the 'endospore' sheath on the host surface. (H) Penetration of the sporoplasm through the host integument and movement towards deeper layers.

host, we nevertheless demonstrated a suitable method to explore a putative built-in mechanism utilized by the parasite to escape from its covering transmission 'vehicle'. Thus, it could be concluded, that the apical opening does not occur passively by an intrinsic mechanism, as many spores with discharged polar filaments did not open and sporoplasm release did not occur. Although polar filament discharge surely facilitates sporoplasm emission, we could show that it is not an imperative prerequisite. Enhanced movement of the sporoplasms and even a rearrangement of the polar capsules inside the valves were frequently observed during incubation of actinospores in fish mucus for several minutes. Thus, the sporoplams apparently were activated without being able to emerge. Hence, this suggests that even within an intact actinospore, the sporoplasm is able to recognize mucus components. It is possible that the sporoplasm may be capable of actively triggering polar filament discharge disposition and thereby affect their infectivity status.

A striking feature of many triactinomyxon-type actinospores is the 'endospore' structure which comprises a membrane-sheathed sporoplasm primary cell with polar capsules attached apically. Its purpose is probably the protection of the sporoplasm after attachment and prior to penetration of the host. El-Matbouli et al. (1999) documented the 'endospore' structure by SEM on the fish host surface after exposure to $M$. cerebralis actinospores and described it as a "fibrous structure", left after the sporoplasm had penetrated. It has also been observed in M. parviformis (Kallert et al. 2005c) by light microscopy, and we observed it in the current study in $M$. pseudodispar and occasionally in M. cerebralis after activation by host mucus. The 'endospore' of $M$. pseudodispar often appears ball-like and is easily emitted by mechanical agitation. Its emission seems to be the result of host anchorage via the polar filament immediately after discharge and its characteristics (shape and mode of emission) differ between the species. As an example, M. cerebralis 'endospores' are rarely seen set free, whereas in $M$. pseudodispar this is very common after incubation in mucus and application of vibrations. Additionally, the amount of force needed for valve opening prior to sporoplasm release may be directly influenced by the sporoplasm itself, as we have shown the sporoplasm can recognize host cues even before polar filament discharge. In addition, sporoplasm emergence directly from the valvular apex directly would be rather difficult due to the forces actuated by water current on the whole valve shell, which is thus avoided in a very elegant manner. Morphological division of actinospores into 'epi-' and 'endospore', formerly suggested by Janiszewska (1955), should be re-established, as it is not referred to in the current myxozoan taxonomy, although their presence and taxonomical impact are clearly visible. We suggest that the functional differences are taxonomically important and suggest them to be included among established parameters such as morphometrics and secondary cell count. Observations on the presence, composition, shape and function of the 'endospore' should be referred to in future actinospore descriptions and transmission studies.

Our findings with the myxozoan species in this study allowed us to compose a refined picture of the steps actinospores take during host invasion (Fig. 6). When in proximity to a host, the waterborne 
actinospores receive chemical cues from host mucus and become mechanically excitable (Fig. 6A). Upon apical contact, a not yet known mechanoreceptor induces fast discharge of the polar filament, which presumably depends on medium osmolality (Fig. $6 \mathrm{~B})$. Subsequent retraction of the filament pulls the apical region of the actinospore tightly into the mucous surface (Fig. 6C). Forces generated by a parachute-like mechanism caused by hydrodynamic forces on the floating appendices open the apical valve shell along their sutures (Fig. 6D) and the actinosporean shell is eventually discarded (Fig. 6E). For this purpose, actinospores possess an apical, species-specific suture lining along which the valves open. The sporoplasm (inside a sheath or 'endospore') is released being tightly attached (thereby physically and osmotically protected) to the host surface. The amoeboid mass leaves the membranous sheath (Fig. $6(\mathrm{~F})$ ) and moves into the host (Fig. 6G) by penetration of the epidermal tissue (Fig. $6 \mathrm{H}$ ) and finally follows a path towards its species-specific target cell type or organ. These mechanisms comprise an excellent set of adaptations for successful passive host recognition and invasion in an aquatic environment without energy-intensive active hostfinding behaviour.

We thank C. Loy for laboratory assistance and J. Borrelli for her help on the topic and culture maintenance. Additional thanks to the Department for Developmental Biology of the FAU Erlangen-Nürnberg and J. Hertel, B. Haberl, R. Rübsam and M. Kalbe for their help. This study was supported by the Deutsche Forschungsgemeinschaft.

\section{REFERENCES}

Belem, A. M. and Pote, L. (2001). Portals of entry and systemic localization of proliferative gill disease organisms in channel catfish Ictalurus punctatus. Diseases of Aquatic Organisms 48, 37-42.

Cannon, Q. and Wagner, E. (2003). Comparison of discharge mechanisms of cnidarian cnidae and myxozoan polar capsules. Reviews in Fisheries Science 11, 185-219.

El-Matbouli, M., Hoffmann, R. W., Schoel, H., McDowell, T. S. and Hedrick, R. P. (1999). Whirling disease: host specificity and interaction between the actinosporean stage of Myxobolus cerebralis and rainbow trout Oncorhynchus mykiss. Diseases of Aquatic Organisms 35, 1-12.

Holzer, A. S., Sommerville, C. and Wootten, R. (2003). Tracing the route of Sphaerospora truttae from the entry locus to the target organ of the host, Salmo salar L., using an optimized and specific in situ hybridization technique. Fournal of Fish Diseases 26, 647-655.

Janiszewska, J. (1955). Actinomyxidia. Morphology, ecology, history of investigations, systematics, development. Acta Parasitologica Polonica 2, 405-443.

Kallert, D. M., El-Matbouli, M. and Haas, W. (2005 a). Polar filament discharge of Myxobolus cerebralis actinospores is triggered by combined non-specific mechanical and chemical cues. Parasitology 131, 609-616. DOI : 10.1017/S0031182005008383

Kallert, D. M., Eszterbauer, E., El-Matbouli, M., Erséus, C. and Haas, W. (2005b). The life cycle of Henneguya nuesslini Schuberg \& Schröder 1905 (Myxozoa) involves a triactinomyxon-type actinospore. Fournal of Fish Diseases 28, 71-79. DOI: 10.1111/j.1365-2761.2004.00599.x

Kallert, D. M., Eszterbauer, E., Erséus, C., El-Matbouli, M. and Haas, W. (2005c). Life cycle studies of Myxobolus parviformis sp.n. from bream. Diseases of Aquatic Organisms 66, 233-243.

Kawaii, S., Yamashita, K., Nakai, N. and Fusetani, N. (1997). Intracellular calcium transients during nematocyst discharge in Actinulae of the hydroid, Tubularia mesembryanthemum. Fournal of Experimental Zoology 278, 299-307.

Kent, M. L., Andree, K. B., Bartholomew, J. L., El-Matbouli, M., Desser, S. S., Devlin, R. H., Feist, S. W., Hedrick, R. P., Hoffmann, R. W., Khattra, J., Hallett, S. L., Lester, R. J. G., Longshaw, M., Palenzeula, O., Siddall, M. E. and Xiao, C. (2001). Recent advances in our knowledge of the Myxozoa. Fournal of Eukaryotic Microbiology 48, 395-413. DOI : 10.1368/1066-5234(2001)048[0395 :RAIOKO]2.0.CO;2

Longshaw, M., Le Deuff, R. M., Harris, A. F. and Feist, S. W. (2002). Development of proliferative kidney disease in rainbow trout, Oncorhynchus mykiss (Walbaum), following short-term exposure to Tetracapsula bryosalmonae infected bryozoans. Fournal of Fish Diseases 25, 443-449.

Markiw, M. E. (1992). Experimentally induced whirling disease II. Determination of longevity of the infective triactinomyxon stage of Myxobolus cerebralis by vital staining. Fournal of Aquatic Animal Health 4, 44-47. DOI : 10.1577/1548-8667(1992)004<0044:EIWDID > 2.3. $\mathrm{CO} ; 2$

Meier-Brook, C. (1978). Calcium uptake by Marisa cornuarietis (Gastropoda; Ampulariidae), a predator of schistosome-bearing snails. Archiv für Hydrobiologie 82, 449-464.

Morris, D. J., Adams, A. and Richards, R. H. (2000). In situ hybridisation identifies the gill as a portal of entry for PKX (Phylum Myxozoa), the causative agent of proliferative kidney disease in salmonids. Parasitology Research 86, 950-956.

Russell, R. J. and Watson, G. M. (1995). Evidence for intracellular stores of calcium ions involved in regulating nematocyst discharge. Fournal of Experimental Zoology 273, 175-185.

Santoro, G. and Salleo, A. (1991). The discharge of in situ nematocysts of the acontia of Aiptasia mutabilis is a $\mathrm{Ca}^{2+}$-induced response. Fournal of Experimental Biology 156, 173-185.

Uspenskaya, A. V. (1982). New data on the life cycle and biology of Myxosporidia. Archiv für Protistenkunde 126, 309-338.

Xiao, C. and Desser, S. S. (2000). The longevity of 7 forms of actinosporean spores from oligochaetes of Lake Sasajewun, Algonquin Park, Ontario, and their reaction to fish mucus. Fournal of Parasitology 86, 193-195. DOI : 10.1645/0022-3395(2000)086[0193 : TLOASF]2.0.CO;2 
Yokoyama, H. (2003). A review: Gaps in our knowledge on Myxozoan parasites of fishes. Fish Pathology (Gyobio Kenkyu) 38, 125-136.

Yokoyama, H. and Urawa, S. (1997). Fluorescent labelling of actinospores for determining the portals of entry into fish. Diseases of Aquatic Organisms 30, 165-169. DOI :10.1023/A:1005752913780

Yokoyama, H., Ogawa, K. and Wakabayashi, H. (1991). A new collection method of actinosporeans - a probable infective stage of myxosporeans to fishes - from tubificids and experimental infection of goldfish with the actinosporean, Raabeia sp. Fish Pathology (Gyobio Kenkyu) 26, 133-138.

Yokoyama, H., Ogawa, K. and Wakabayashi, H. (1993). Some biological characteristics of actinosporeans from the oligochaete Branchiura sowerbyi. Diseases of Aquatic Organisms 17, 223-228.

Yokoyama, H., Kim, H. J. and Urawa, S. (2006). Differences in host selection of two myxosporeans, Myxobolus arcticus and Thelohanellus hovorkai. Fournal of Parasitology 92, 725-729. DOI: 10.1645/ GE-831R.1 